\title{
(6) OPEN ACCESS \\ Ethnic inequalities in limiting health and self-reported health in later life revisited
}

\author{
Maria Evandrou, ${ }^{1,2}$ Jane Falkingham, ${ }^{2}$ Zhixin Feng, $^{1}$ Athina Vlachantoni ${ }^{1,2}$
}

- Additional material is published online only. To view please visit the journal online (http://dx.doi.org/10.1136/jech2015-206074)

${ }^{1}$ Faculty of Social, Human and Mathematical Sciences Centre for Research on Ageing, University of Southampton, Southampton, UK

${ }^{2}$ Faculty of Social, Human and Mathematical Sciences ESRC Centre for Population Change, University of Southampton, Southampton, UK

\section{Correspondence to} Professor Maria Evandrou, Centre for Research on Ageing, Faculty of Social, Human and Mathematical Sciences University of Southampton, Southampton, SO17 1BJ, UK; maria.evandrou@soton.ac.uk

Received 19 May 2015 Revised 26 October 2015 Accepted 22 December 2015 Published Online First 19 January 2016

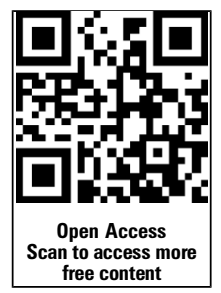

\section{ABSTRACT \\ Background It is well established that there are ethnic inequalities in health in the UK; however, such inequalities in later life remain a relatively under- researched area. This paper explores ethnic inequalities in health among older people in the UK, controlling for social and economic disadvantages.}

Methods This paper analyses the first wave (20092011) of Understanding Society to examine differentials in the health of older persons aged 60 years and over. 2 health outcomes are explored: the extent to which one's health limits the ability to undertake typical activities and self-rated health. Logistic regression models are used to control for a range of other factors, including income and deprivation.

Results After controlling for social and economic disadvantage, black and minority ethnic (BME) elders are still more likely than white British elders to report limiting health and poor self-rated health. The 'health disadvantage' appears most marked among BME elders of South Asian origin, with Pakistani elders exhibiting the poorest health outcomes. Length of time resident in the UK does not have a direct impact on health in models for both genders, but is marginally significant for women.

Conclusions Older people from ethnic minorities report poorer health outcomes even after controlling for social and economic disadvantages. This result reflects the complexity of health inequalities among different ethnic groups in the UK, and the need to develop health policies which take into account differences in social and economic resources between different ethnic groups.

\section{INTRODUCTION}

Ethnic inequalities in health have been well documented in the UK. ${ }^{1-5}$ Individuals from black and minority ethnic (BME) groups have generally been found more likely to report poor general health than the white British population, ${ }^{6}$ and those of black Caribbean, black African, Indians, Pakistani and Bangladeshi heritage have also been found more likely to report a limiting long-term illness than the white British group. ${ }^{78}$ It has been argued that ethnic inequalities in health in part reflect other inequalities between ethnic groups, that is, in terms of socioeconomic position and social class, health service access and use, and racial discrimination. ${ }^{9}$ For example, unemployment among BME individuals is generally higher than among white British individuals, ${ }^{10}$ and the proportion of BME persons living in low-income households is also higher than among white British persons. ${ }^{11}$ Even within the same social class, research has shown that BME individuals have a lower income than their white British counterparts. ${ }^{4}$ Although socioeconomic inequalities may make a minimal or no contribution to ethnic inequalities in health, ${ }^{12}$ a clear association has been found between poor selfrated health and limiting long-term illness on one hand, and social and economic disadvantage on the other. ${ }^{13}{ }^{14}$ Individuals from some ethnic minorities are also exposed to social and economic disadvantages over the life course which can result in a higher likelihood of reporting poor self-rated health and limiting long-term illness. ${ }^{8}{ }^{15}$ Nazroo $^{8}$ concluded that social and economic inequalities underpinned by ethnicity are fundamental causes of ethnic inequalities in health in the UK.

Moreover, BME individuals report a poorer healthcare experience than white British persons, and are also less likely to use GP services. ${ }^{16}$ The lack of accessible information, language barriers, poorer knowledge about services, inadequate surgery premises and longer waits for appointments all contribute to difficulties in terms of healthcare access. ${ }^{11} 17$ Without adequate healthcare, BME individuals could be slower to recover from health issues than their white British counterparts, and delays in treatment could also lead to an accumulation of limiting health in later life. At the same time, racial discrimination could be manifested indirectly (eg, through socioeconomic disadvantage) or directly (eg, through racial discrimination and harassment). ${ }^{4}$ Indeed, Karlsen and Nazroo ${ }^{18}$ found that persons from ethnic minority (EM) groups who reported experiences of racism also self-reported negative health, while BME individuals who had experienced verbal abuse or had been physically attacked were more likely to report their health as fair or poor than those who reported no such attack. Such harmful effects of racial discrimination may not only influence ethnic minorities' current health, but could also affect their health in later life through the accumulation of negative effects.

It has been noted in the literature that the experience of migration itself might have a direct impact on one's health through associated social and economic upheavals. ${ }^{9}$ Furthermore, the timing of migration and associated length of residence in the UK may affect exposure to both socioeconomic and wider environmental influences. It has been suggested that migration could relate to upward social mobility, which could result in a lower exposure to social disadvantage for individuals from ethnic minorities in their life course. ${ }^{19}{ }^{20}$ Migration which results in long periods of residency in the destination context may also determine whether individuals from ethnic minorities could be eligible to receive a state pension or occupational pension in their later life. $^{21} 22$ 
In the last decade (2001-2011), the proportion of individuals from BME groups has risen from $8 \%$ in 2001 to $14 \%$ (approximately by 7.8 million) of the total population in England and Wales in 2011. ${ }^{23}$ Although BME groups generally display a younger age structure, with only $5 \%$ of individuals from minority ethnic groups being aged 65 years and over in $2011,{ }^{24}$ the BME population is ageing along with the rest of the white British population, and it has been predicted that there will be 3.8 million BME individuals aged 65 years and over by $2051 .^{25}$ Existing research has found significant socioeconomic disadvantages faced by BME elders (Vlachantoni, et al. Forthcoming 2016). ${ }^{26} 27$

Despite a relatively large body of research on ethnic inequalities, the extent of such inequalities in later life remains a relatively under-researched area with most studies concentrating on the population of working age. In part, this reflects the absence of nationally representative data containing information on health and ethnicity and with sufficient sample sizes to identify ethnic elders. Evandrou ${ }^{20}$ used pooled data from 6 years of the General Household Survey (1991-1996) and found that BME older people reported worse health than the white British majority population, with Pakistani and Bangladeshi elders consistently reporting the worst health outcomes in terms of longstanding illness, ill health and 'not good' general health status. Despite the ageing of the BME population, since the publication of Evandrou ${ }^{20}$ there have been no further studies that have explicitly examined health inequalities among ethnic groups in later life. This paper, therefore, aims to update and build on Evandrou's previous analysis. Revisiting the patterning of health inequalities among BME groups in later life is critical not only in terms of updating our understanding of health differentials among EM elders, but also in terms of informing the development of healthcare provision for particularly vulnerable BME groups.

\section{METHODS}

\section{Data source}

The data used are drawn from the first wave (collected from 2009 to 2011) of Understanding Society. This is a national survey including an Ethnic Minority Boost Sample, thus

Table 1 Descriptive univariate information of individual variables

\begin{tabular}{|c|c|}
\hline \multicolumn{2}{|l|}{ Health outcomes } \\
\hline Health limits typical activities & No limitation $(60.9 \%)$, some limitation $(39.1 \%)$ \\
\hline Self-reported general health & Good $(87.8 \%)$, poor $(12.2 \%)$ \\
\hline \multicolumn{2}{|l|}{ Predictors } \\
\hline Age (years) & Ranging between 60 and 101, mean $=70$ \\
\hline Gender & Male $(46 \%)$; female $(54 \%)$ \\
\hline Ethnicity & $\begin{array}{l}\text { White British }(90 \%) \text {, Irish }(1.7 \%) \text {, other white }(1.2 \%) \text {, mixed }(0.4 \%) \text {, Indian }(1.8 \%) \text {, Pakistani }(0.9 \%) \text {, Bangladeshi }(0.4 \%) \text {, } \\
\text { other Asian }(0.4 \%) \text {, Caribbean }(1.8 \%) \text {, African }(0.6 \%) \text {, other ethnic group }(0.9 \%)\end{array}$ \\
\hline Income $(f)$ & Ranging between 0 and 15 000; mean=1200; quintiles: 455, 757, 1060, 1627 \\
\hline Time resident in the UK & Born in the UK $(89.5 \%)$, less than 10 years $(0.3 \%), 10-39$ years $(2.5 \%), 40-49$ years $(4.0 \%), 50+$ years $(3.7 \%)$ \\
\hline \multicolumn{2}{|l|}{ Deprivation information } \\
\hline \multicolumn{2}{|l|}{ Information from household questionnaire } \\
\hline Have central heating & Yes $(92 \%)$, no $(8 \%)$ \\
\hline Have car(s) & Yes $(75 \%)$, no $(25 \%)$ \\
\hline Have colour television & Yes $(98.8 \%)$, no $(1.2 \%)$ \\
\hline Have video recorder/DVD player & Yes $(89 \%)$, no (11\%) \\
\hline Have satellite dish/sky TV & Yes $(36.9 \%)$, no $(63.1 \%)$ \\
\hline Have cable TV & Yes $(14.4 \%)$, no $(85.6 \%)$ \\
\hline Have deep freeze or fridge freezer & Yes $(95 \%)$, no $(5 \%)$ \\
\hline Have washing machine & Yes $(94.8 \%)$, no $(5.2 \%)$ \\
\hline Have tumble drier & Yes $(54.1 \%)$, no $(45.9 \%)$ \\
\hline Have dishwasher & Yes $(39.4 \%)$, no $(60.6 \%)$ \\
\hline Have microwave oven & Yes $(92 \%)$, no $(8 \%)$ \\
\hline Have home computer/PC (not games console) & Yes $(57.4 \%)$, no $(42.6 \%)$ \\
\hline Have compact disc player & Yes $(65.6 \%)$, no $(34.4 \%)$ \\
\hline Have landline telephone & Yes $(95 \%)$, No $(5 \%)$ \\
\hline Have mobile telephone (anyone in household) & Yes $(82.5 \%)$, no (17.5\%) \\
\hline Have access to Internet & Yes $(53.1 \%)$, No $(46.9 \%)$ \\
\hline \multicolumn{2}{|l|}{ Information from individual questionnaire } \\
\hline Have holiday & I/we have this $(65.5 \%)$, I/we do not want this at the moment $(22.2 \%)$, can't afford it $(12.4 \%)$ \\
\hline Have friends/family around for drink or meal & I/we have this $(64.6 \%)$, I/we do not want this at the moment $(31 \%)$, can't afford it $(4.5 \%)$ \\
\hline Have all weather shoes & I/we have this $(97 \%)$, I/we do not want this at the moment $(1.4 \%)$, can't afford it $(1.5 \%)$ \\
\hline Have house in decent state of repair & I/we have this $(91 \%)$, I/we do not want this at the moment $(1.9 \%)$, can't afford it $(7.1 \%)$ \\
\hline Have household contents insurance & I/we have this $(90.2 \%)$, I/we do not want this at the moment $(5.4 \%)$, can't afford it $(4.4 \%)$ \\
\hline Have regular savings & I/we have this $(75.9 \%)$, I/we do not want this at the moment $(8.1 \%)$, can't afford it $(16 \%)$ \\
\hline Have replace worn out furniture & I/we have this $(79.6 \%)$, I/we do not want this at the moment $(6.6 \%)$, can't afford it $(13.8 \%)$ \\
\hline Have replace or repair major electrical goods & I/we have this $(86.7 \%)$, I/we do not want this at the moment $(3.4 \%)$, can't afford it $(9.9 \%)$ \\
\hline Summary experience of deprivation score: & Ranging between 0 and 23 , mean=5.5; quartiles: 3,5 and 7.5 . \\
\hline
\end{tabular}


making it an ideal data set for this study. The sample includes two parts: the General Population (GP) sample selected from the Postcode Address File (PAF) in Great Britain (GB) and the Land and Property Services Agency (LPSA) list of domestic properties in Northern Ireland (NI), and a boost sample of minority ethnic groups (EM). In each household, all individuals aged 10 years and over were eligible for interview. The survey was designed to include at least 1000 individuals from five key ethnic groups: Indian, Pakistani, Bangladeshi, Caribbean and African. ${ }^{28}$ There are 47678 respondents in this data set with complete information: 10804 are aged 60 years and over, of which 581 came from the five ethnic groups aforementioned. The analysis was carried out with weighted data, with weights taking into account the EM boost, and adjusting for household level non-response and within-household non-response at wave $1 .{ }^{29}$

\section{Health outcomes measures}

Health outcomes include whether one's health limits their typical activities and self-rated health. The former variable is commonly used in studies of older people to gauge their need for support in terms of typical activities. Respondents were asked: "Does your health now limit you a lot, limit you a little or not limit you at all in moderate activities such as moving a table, pushing a vacuum cleaner, bowling or playing golf...that you might do during a typical day?" The response categories were recoded into a binary variable: 0 representing the report of no limitation at all, and 1 representing some limitation
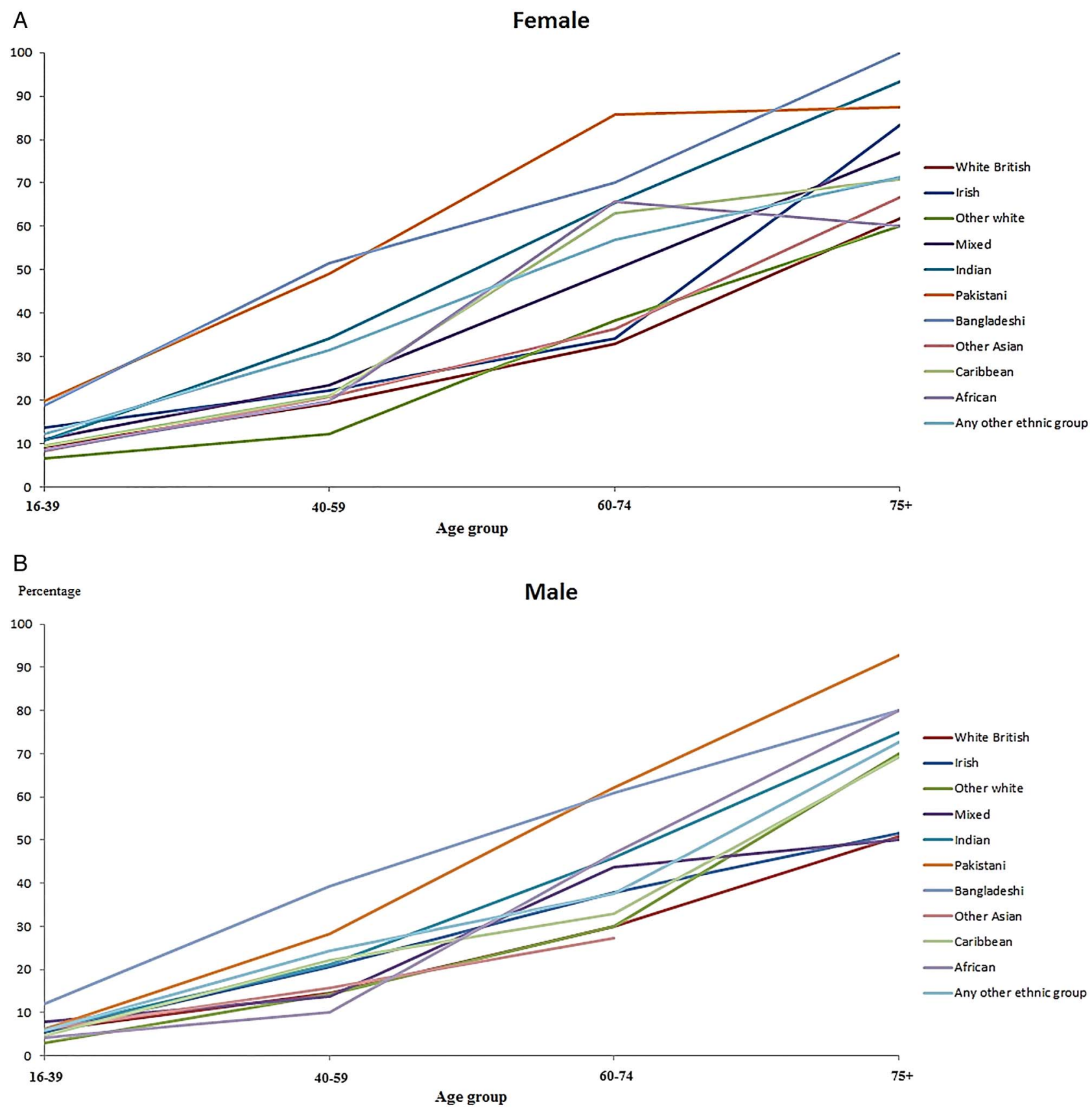

Figure 1 (A) (Women) and (B) (men): Percentage reporting that health limits typical activities by age and ethnicity, Great Britain $\left(\chi^{2}\right.$ significant at $\mathrm{p}<0.001)$. Understanding Society (2009-2011; total number for men: 20 854; total number for women 26 550; there are no Pakistani men in the sample aged $75+$ years). 
(limited a lot or a little). Self-rated health is a sensitive and reliable indicator of current health status, particularly for elderly people. ${ }^{30}{ }^{31}$ Respondents were asked: "In general, would you say your health is excellent, very good, good, fair, or poor?" For ease of comparability with previous studies, the categories were recoded into a binary outcome: 0 for excellent, very good, good or fair, and 1 for poor. The distribution for these two health indicators across the analytical sample aged 60 years and over is shown in table 1.

\section{Independent variables}

Ethnicity is the key variable in the analysis. It was recoded according to the respondents' self-report of their ethnic group into white British, Irish, other Caucasian, mixed, Indian,
Pakistani, Bangladeshi, other Asian, Caribbean, African and other ethnic groups.

The length of time respondents have been in the UK variable indicates the experience of migration and residence in the UK. It combines two pieces of information: whether the respondent was born in the UK and if not, the length of time (in years) that they have been resident the UK (recoded as: less than 10, 10$39,40-49$ and 50 years or more).

Income and deprivation are two key socioeconomic status variables used. Income reflects the total individual gross monthly income. Deprivation is a derived variable which summarises the experience of deprivation from 16 question items in the household questionnaire and 8 question items from the individual questionnaire in the data set. The choice of the items to examine individual deprivation is largely based on the
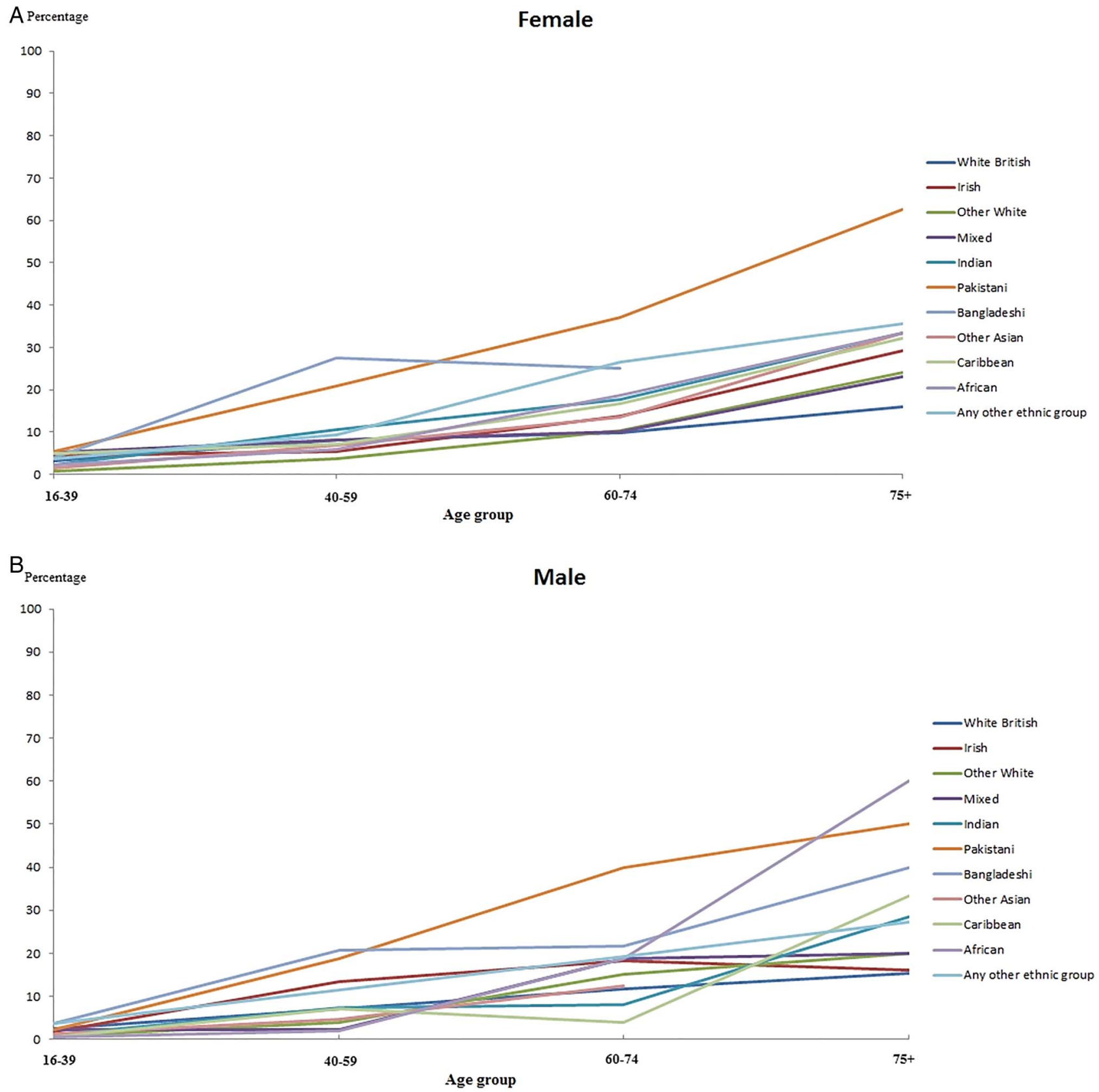

Figure 2 (A) (Women) and (B) (men): Percentage reporting poor self-rated health by age and ethnicity, Great Britain $\left(\chi^{2}\right.$ significant at $\left.p<0.001\right)$. Understanding Society (2009-2011; total number for men: 21 008; total number for women 26 670; there are no Bangladeshi women and other Asian men aged $75+$ years in the sample). 
Table 2 Percentage of persons aged 60 years and over-reporting that health limits typical activities by age, sex and ethnicity (\%)

\begin{tabular}{|c|c|c|c|c|c|c|c|c|c|c|c|c|}
\hline & $\begin{array}{l}\text { White } \\
\text { British }\end{array}$ & Irish & $\begin{array}{l}\text { Other } \\
\text { white }\end{array}$ & Mixed & Indian & Pakistani & Bangladeshi & $\begin{array}{l}\text { Other } \\
\text { Asian }\end{array}$ & Caribbean & African & $\begin{array}{l}\text { Any other } \\
\text { ethnic group }\end{array}$ & $\chi^{2}$ Significant $\mathrm{p}<$ \\
\hline Men & & & & & & & & & & & & 0.05 \\
\hline $60-74$ & 30 & 38 & 30 & 44 & 45 & 62 & 61 & 29 & 34 & 47 & 36 & \\
\hline 75 and over & 51 & 52 & 70 & 50 & 78 & 93 & 80 & 0 & 69 & 80 & 73 & \\
\hline All aged 60+ & 36 & 42 & 38 & 46 & 52 & 69 & 67 & 27 & 46 & 51 & 43 & \\
\hline Women & & & & & & & & & & & & 0.001 \\
\hline $60-74$ & 33 & 34 & 38 & 50 & 65 & 86 & 70 & 36 & 63 & 66 & 56 & \\
\hline 75 and over & 62 & 83 & 60 & 77 & 93 & 88 & 100 & 67 & 71 & 60 & 71 & \\
\hline All aged 60+ & 42 & 46 & 44 & 61 & 70 & 86 & 71 & 40 & 65 & 65 & 59 & \\
\hline All & & & & & & & & & & & & 0.001 \\
\hline $60-74$ & 32 & 36 & 35 & 47 & 55 & 73 & 65 & 33 & 50 & 56 & 46 & \\
\hline 75 and over & 57 & 65 & 63 & 65 & 83 & 91 & 82 & 40 & 70 & 70 & 72 & \\
\hline All aged 60+ & 39 & 44 & 42 & 54 & 60 & 76 & 69 & 33 & 56 & 58 & 51 & \\
\hline
\end{tabular}

Understanding Society (2009-2011; total number for men: 4975; total number for women: 5840).

construction of a deprivation index by Berthoud and Bryan ${ }^{32}$ that covers daily living, financial strain and durables. ${ }^{i}$

Age and gender are included in order to observe their independent effect on an individual's chances of reporting poor health outcomes. The analysis was also run separately for men and women in order to unravel gender differences. The distribution of these independent variables is also shown in table 1.

For the descriptive analysis, cross-tabulations were used in order to obtain the distributions of health outcomes among different ethnic groups. For the exploratory analysis of ethnic inequalities in terms of health outcomes, logistic regression models were applied to examine the association between ethnicity and health outcomes. All the models were estimated in the SPSS V.22 software.

\section{RESULTS}

\section{Patterns of health inequality among the whole population}

Figure 1A, B indicates the percentage of individuals reporting that their health limits their typical activities; the percentage rises with increasing age across all ethnic groups. A greater variance and greater ethnic differentials are found among women than among men. For both men and women, a higher proportion of individuals from BME groups report that their health limits their typical activities compared with the white British population. Furthermore, the ethnic differential in health widens with increasing age, highlighting the importance of focusing on later life.

In terms of self-rated health, figure $2 \mathrm{~A}, \mathrm{~B}$ indicates the percentage of individuals reporting poor self-rated health for women and men. Again a higher proportion of BME individuals report poor self-rated health compared with the white British group, and the ethnic differential in health widens with increasing age for both women and men.

${ }^{\mathrm{i}}$ Each item in the household was initially scored between 1 and 0 , where 1 indicated an item which the household did not have, and 0 an item which the household did have; each item at the individual level was also initially scored between 1 and 0 , where 1 indicated an item which the individual could not afford; 0.5 indicated an item which the individual did not want at the moment; and 0 indicated an item which the individual had. Therefore, the higher the total score, the higher the deprivation experienced by the respondent.

\section{Health outcomes among the older population}

Tables 2 and 3 show the proportion of people aged 60 years and the over-reporting of limiting health and 'poor' self-rated health by ethnicity. Table 2 shows that Pakistani and Bangladeshi elders, both among men and women, experience a clear disadvantage compared with other ethnic groups. Other Asian and Irish individuals are the closest to the white majority in this respect. In terms of reporting self-rated health, table 3 shows a similar disadvantage for Pakistani and Bangladeshi elders, among both women and men (although such results are not statistically significant when the models are separated by gender). The prevalence ratios were also consistently higher for Pakistani and Bangladeshi elders, of both sexes, in terms of reporting poor health and limiting health outcomes compared with white British elders (see online supplementary tables S6-7).

\section{Socioeconomic differentials among ethnic groups}

Figure 3 presents the proportion of BME elders within each quintile group of the income distribution for the population as a whole. More than 35\% of Indian, Pakistani and Bangladeshi elders are in the poorest fifth of the income distribution compared with $19 \%$ of white British, $12 \%$ of mixed and $22 \%$ of other Asian elders. There are some interesting differences within the BME population, with other Asian (25\%) and other white $(26 \%)$ older people recording the highest proportion in the richest fifth of the income distribution, compared with just $7.6 \%$ of Pakistani, and about $12 \%$ of Bangladeshi and Caribbean elders.

In terms of the experience of deprivation, more than $32 \%$ of white British, other white and Indian older people are located in the lowest quartile of deprivation, compared with just over $3 \%$ of African elders. By contrast, more than 50\% of Pakistani, Bangladeshi, Caribbean and African elders are found in the highest quartile of deprivation (figure 4), again highlighting the need to distinguish between the experience of different BME groups.

It is clear that there is substantial social disadvantage among older individuals from different EM communities. Given the strong relationship between one's socioeconomic status and health, whether ethnic inequalities in health in later life can be explained by differentials of socioeconomic status is a key question. It is important to explore health inequalities among ethnic communities before and after controlling for socioeconomic status in order to ascertain whether improving the income or 
Table 3 Percentage of persons aged 60 years and over-reporting 'poor' health by age, sex and ethnicity (\%)

\begin{tabular}{|c|c|c|c|c|c|c|c|c|c|c|c|c|}
\hline & $\begin{array}{l}\text { White } \\
\text { British }\end{array}$ & Irish & $\begin{array}{l}\text { Other } \\
\text { white }\end{array}$ & Mixed & Indian & Pakistani & Bangladeshi & $\begin{array}{l}\text { Other } \\
\text { Asian }\end{array}$ & Caribbean & African & $\begin{array}{l}\text { Any other } \\
\text { ethnic group }\end{array}$ & $\chi^{2}$ Significant $p<$ \\
\hline Men & & & & & & & & & & & & 0.02 \\
\hline $60-74$ & 12 & 18 & 15 & 19 & 8 & 40 & 22 & 13 & 4 & 19 & 19 & \\
\hline 75 and over & 15 & 16 & 20 & 20 & 30 & 50 & 40 & 0 & 33 & 60 & 27 & \\
\hline All aged $60+$ & 13 & 18 & 16 & 19 & 13 & 42 & 27 & 12 & 14 & 24 & 21 & \\
\hline Women & & & & & & & & & & & & 0.33 \\
\hline $60-74$ & 10 & 14 & 11 & 10 & 18 & 37 & 25 & 14 & 17 & 19 & 27 & \\
\hline 75 and over & 16 & 29 & 24 & 23 & 33 & 63 & 100 & 33 & 32 & 40 & 36 & \\
\hline All aged $60+$ & 12 & 18 & 14 & 15 & 20 & 42 & 29 & 16 & 21 & 22 & 29 & \\
\hline All & & & & & & & & & & & & 0.14 \\
\hline $60-74$ & 12 & 18 & 15 & 19 & 8 & 40 & 22 & 13 & 4 & 19 & 19 & \\
\hline 75 and over & 15 & 16 & 20 & 20 & 30 & 50 & 40 & 0 & 33 & 60 & 27 & \\
\hline All aged $60+$ & 13 & 18 & 16 & 19 & 13 & 42 & 27 & 12 & 14 & 24 & 21 & \\
\hline
\end{tabular}

Understanding Society (2009-2011; total number for men: 4975; total number for women: 5840).

reducing the deprivation of BME elders could reduce health inequalities between ethnic groups, or whether the reporting of poorer health outcomes among particular ethnic groups remains even after controlling for socioeconomic status.

\section{Multivariate analysis}

Two models are presented: model 1 includes age, gender, ethnicity and the length of time resident in the UK to explore ethnic inequalities in health outcomes; model 2 adds income (in quintiles) and deprivation (in quartiles) to model 1 in order to examine whether health inequalities among ethnic groups can be explained fully or partly by socioeconomic disadvantages in later life. Finally, model 2 is run separately for men and women in order to capture gender differentials between and within different ethnic groups.

The results in tables 4 and 5 indicate that once differences in age, gender, the length of time resident in the UK, income and deprivation are controlled for, there remains significant ethnic differences in health among people aged 60 years and over. This suggests that although ethnic inequalities in socioeconomic status make a significant contribution to ethnic inequalities in health, other factors are also important. Moreover, the effects are manifested differently for different ethnic groups.

In terms of one's health limiting their typical activities, the relative odds increase with age and older females are more likely to report that their health limits their typical activities than males. Most BME elders (mixed, Indian, Pakistani, Bangladeshi, Caribbean, African and any other ethnic group) are also more likely to report such an outcome than white British elders, with the odds of Pakistani older people reporting that their health limits their typical activities being seven times higher than that of the white British elders (model 1). No significant differences are found for the length of time older people have been resident in the UK. After controlling for income and deprivation factors (model 2), the pattern does not change substantially, but the differentials do become smaller. For example, the odds of Pakistani elders reporting that their health limits their typical activities are now five times higher than that among white British elders. Older people in the top income quintile have significantly lower odds of reporting their health as limiting than the other income groups. Along the same lines, older people experiencing higher degrees of deprivation are more likely to report that their health limits their typical activities.

For the models by gender, the results remained broadly similar, with a few exceptions: among BME men, only Indian, Pakistani and Bangladeshi men are more likely to report their health as limiting their typical activities than the white British men. The odds of older Pakistani women reporting limiting health are 11 times higher than that among older white British women; older Indian, Bangladeshi and Caribbean women also record elevated odds.
Figure 3 Percentage of persons aged 60 years and over by income quintile and ethnicity (generated from income distribution of all aged 60 years and above). Understanding Society (2009-2011).

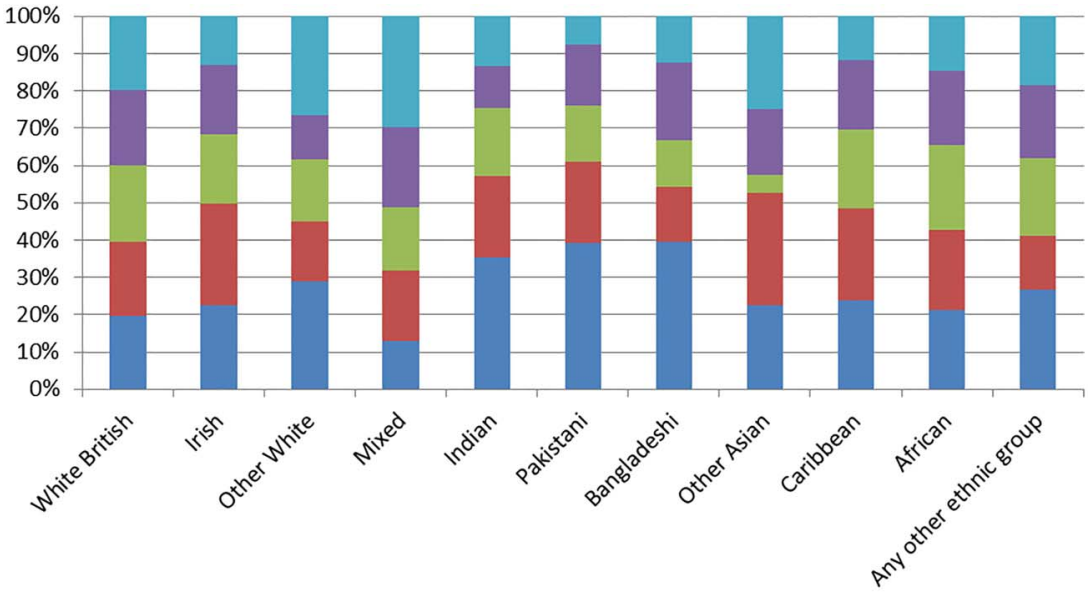

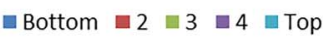


Figure 4 Percentage of persons aged 60 years and over by ethnicity and quartile of summed experience of deprivation (quartiles: $0-3$ (least deprived), 3-5, 5-8 and above 8 (most deprived)). Understanding Society (2009-2011).

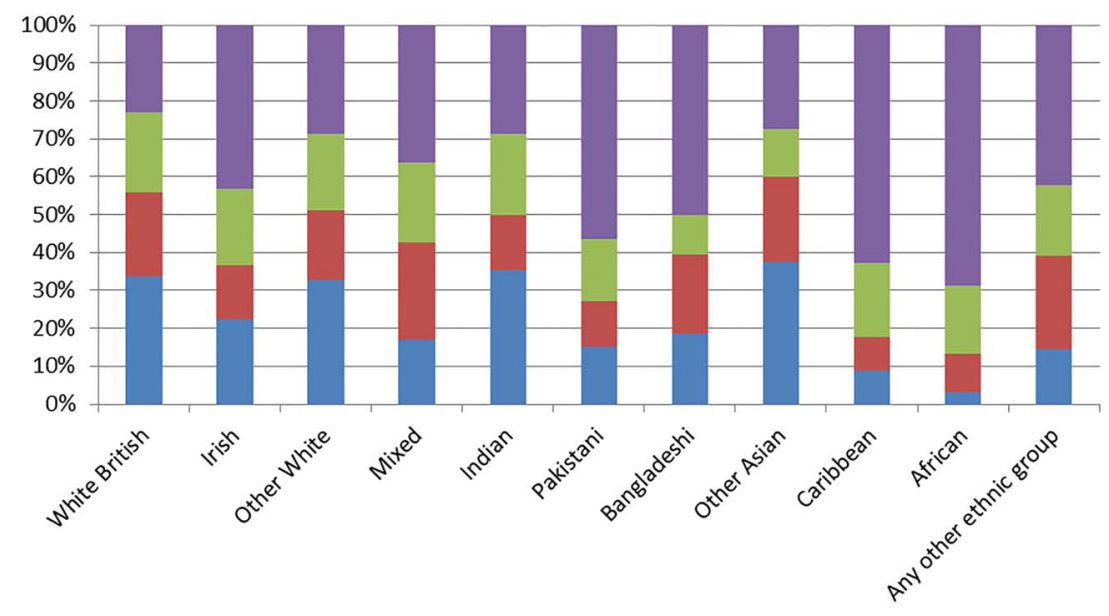

—Least $\square$ 2nd Quartile $\square$ 3rd Quartile $\quad$ Highest
No significant differences are found for the length of time older men have been resident in the UK, but non-UK-born older women, who have spent between 10 and 39 years in the UK, are $71 \%$ more likely to report their health as limiting their typical activities than women born in the UK (table 4).

From table 5, it can be seen that the relative odds of reporting poor self-rated health also increase with age, and women are more likely to report poor self-rated health than men (model 2). Most BME elders are more likely to report poor self-rated health than the white British group (Pakistani, Bangladeshi, African and any other ethnic group), particularly Pakistani elders (OR 6.05; model 1). Again, no significant differences on self-reported health are found for the length of residence in the UK. After controlling for income and deprivation (model 3), the

Table 4 ORs of reporting that health limits typical activities among persons aged 60 years and over

\begin{tabular}{|c|c|c|c|c|}
\hline & \multirow[b]{2}{*}{$\begin{array}{l}\text { Model } 1 \\
\text { ORs }(95 \% \mathrm{Cl})\end{array}$} & \multirow[b]{2}{*}{$\begin{array}{l}\text { Model } 2 \\
\text { ORs }(95 \% \mathrm{CI})\end{array}$} & \multicolumn{2}{|l|}{ Model 2} \\
\hline & & & $\begin{array}{l}\text { Men } \\
\text { ORs }(95 \% \mathrm{Cl})\end{array}$ & $\begin{array}{l}\text { Women } \\
\text { ORs }(95 \% \mathrm{Cl})\end{array}$ \\
\hline Age & $1.08(1.07 \text { to } 1.08)^{* * *}$ & $1.06(1.05 \text { to } 1.06)^{* * *}$ & $1.05(1.04 \text { to } 1.06)^{* * *}$ & $1.07(1.06 \text { to } 1.07)^{* * *}$ \\
\hline \multicolumn{5}{|l|}{ Gender (ref: men) } \\
\hline Women & $1.31(1.20 \text { to } 1.42)^{* * *}$ & $1.17(1.07 \text { to } 1.27)^{* * *}$ & & \\
\hline \multicolumn{5}{|l|}{ Ethnicity (ref: white British) } \\
\hline Irish & 1.34 (0.97 to 1.86$)$ & 1.12 (0.80 to 1.55$)$ & 0.95 (0.59 to 1.53$)$ & 1.27 (0.80 to 2.01$)$ \\
\hline Other white & $1.32(0.85$ to 2.04$)$ & 1.35 (0.86 to 2.11$)$ & 1.31 (0.61 to 2.82$)$ & 1.33 (0.77 to 2.33 ) \\
\hline Mixed & $1.88(1.01 \text { to } 3.49)^{*}$ & 1.73 (0.92 to 3.25$)$ & $1.63(0.64$ to 4.11$)$ & 1.89 (0.78 to 4.54$)$ \\
\hline Indian & $2.88(1.91 \text { to } 4.35)^{* * *}$ & $2.81(1.84 \text { to } 4.28)^{* * *}$ & $2.60(1.42 \text { to } 4.78)^{* *}$ & $3.41(1.84 \text { to } 6.33)^{* * *}$ \\
\hline Pakistani & $7.00(3.89 \text { to } 12.6)^{* * *}$ & $5.46(3.00 \text { to } 9.92)^{* * *}$ & $4.27(1.98 \text { to } 9.19)^{* * *}$ & $11.05(3.52 \text { to } 34.68)^{* * *}$ \\
\hline Bangladeshi & $3.20(1.66 \text { to } 6.17)^{* * *}$ & $2.66(1.36 \text { to } 5.20)^{* *}$ & $3.22(1.36 \text { to } 7.67)^{* *}$ & $1.76(0.57$ to 5.46$)$ \\
\hline Other Asian & 0.80 (0.37 to 1.72$)$ & 0.75 (0.34 to 1.66$)$ & 0.83 (0.27 to 2.57$)$ & 0.69 (0.22 to 2.12$)$ \\
\hline Caribbean & $2.19(1.48 \text { to } 3.25)^{* * *}$ & $1.59(1.06 \text { to } 2.37)^{*}$ & 0.99 (0.55 to 1.79$)$ & $2.47(1.40 \text { to } 4.35)^{* *}$ \\
\hline African & $2.14(1.19 \text { to } 3.86)^{*}$ & 1.44 (0.79 to 2.61$)$ & 1.21 (0.51 to 2.90$)$ & 1.77 (0.76 to 4.13$)$ \\
\hline Any other ethnic group & $1.76(1.10 \text { to } 2.83)^{*}$ & 1.50 (0.92 to 2.43 ) & 1.36 (0.66 to 2.79$)$ & 1.73 (0.88 to 3.41$)$ \\
\hline \multicolumn{5}{|c|}{ Time resident in the UK (ref: born in the UK) } \\
\hline Less than 10 years & $0.90(0.42$ to 1.94$)$ & 0.80 (0.37 to 1.72 ) & 0.58 (0.19 to 1.77$)$ & 0.92 (0.30 to 2.80$)$ \\
\hline $10-39$ years & $1.27(0.87$ to 1.85$)$ & 1.20 (0.82 to 1.77 ) & 0.76 (0.42 to 1.37$)$ & $1.71(1.00 \text { to } 2.91)^{*}$ \\
\hline $40-49$ years & 0.97 (0.70 to 1.36$)$ & 0.95 (0.68 to 1.34 ) & 0.86 (0.51 to 1.45$)$ & 0.97 (0.61 to 1.54$)$ \\
\hline $50+$ years & $0.92(0.70$ to 1.21$)$ & 0.91 (0.69 to 1.20$)$ & 0.97 (0.64 to 1.47 ) & 0.86 (0.59 to 1.26 ) \\
\hline \multicolumn{5}{|l|}{ Income quintile (ref: top) } \\
\hline Fourth quintile & & $1.43(1.24 \text { to } 1.64)^{\star * *}$ & $1.51(1.27 \text { to } 1.81)^{* * *}$ & $1.28(1.02 \text { to } 1.60)^{*}$ \\
\hline Third quintile & & $1.31(1.14 \text { to } 1.51)^{* * *}$ & $1.34(1.11 \text { to } 1.62)^{* *}$ & 1.22 (0.98 to 1.52$)$ \\
\hline Second quintile & & $1.38(1.20 \text { to } 1.59)^{* * *}$ & $1.60(1.30 \text { to } 1.97)^{* * *}$ & 1.19 (0.96 to 1.47$)$ \\
\hline Bottom & & $1.29(1.12 \text { to } 1.49)^{* * *}$ & $1.49(1.18 \text { to } 1.87)^{* * *}$ & 1.12 (0.91 to 1.38$)$ \\
\hline \multicolumn{5}{|c|}{ Deprivation (ref: first quartile (lowest)) } \\
\hline Second quartile & & $1.28(1.14 \text { to } 1.45)^{* * *}$ & $1.28(1.08 \text { to } 1.52)^{* *}$ & $1.29(1.09 \text { to } 1.52)^{* *}$ \\
\hline Third quartile & & $1.71(1.52 \text { to } 1.93)^{\star \star *}$ & $1.78(1.49 \text { to } 2.13)^{* * *}$ & $1.63(1.39 \text { to } 1.92)^{* * *}$ \\
\hline Fourth quartile & & $2.63(2.33 \text { to } 2.96)^{* * *}$ & $2.90(2.42 \text { to } 3.48)^{* * *}$ & $2.39(2.04 \text { to } 2.80)^{* * *}$ \\
\hline
\end{tabular}


Table 5 ORs of reporting 'poor health' over the last year among persons aged 60 years and over

\begin{tabular}{|c|c|c|c|c|}
\hline & \multirow[b]{2}{*}{$\begin{array}{l}\text { Model } 1 \\
\text { ORs }(95 \% \mathrm{Cl})\end{array}$} & \multirow[b]{2}{*}{$\begin{array}{l}\text { Model } 2 \\
\text { ORs }(95 \% \mathrm{Cl})\end{array}$} & \multicolumn{2}{|l|}{ Model 2} \\
\hline & & & $\begin{array}{l}\text { Men } \\
\text { ORs }(95 \% \mathrm{Cl})\end{array}$ & $\begin{array}{l}\text { Women } \\
\text { ORs }(95 \% \mathrm{Cl})\end{array}$ \\
\hline Age & $1.03(1.03$ to 1.04$) * * *$ & $1.01(1.00$ to 1.02$) * *$ & $1.00(0.99$ to 1.02$)$ & $1.02(1.01$ to 1.03$)$ ** \\
\hline \multicolumn{5}{|l|}{ Gender (ref: men) } \\
\hline Women & $0.93(0.83$ to 1.04$)$ & $0.85(0.75$ to 0.96$)$ * & & \\
\hline \multicolumn{5}{|l|}{ Ethnicity (ref: white British) } \\
\hline Irish & $1.42(0.93$ to 2.17$)$ & $1.15(0.75$ to 1.77$)$ & 1.07 (0.57 to 1.98$)$ & $1.28(0.70$ to 2.33$)$ \\
\hline Other white & $1.12(0.62$ to 2.03$)$ & $1.14(0.62$ to 2.09$)$ & $1.13(0.38$ to 3.37$)$ & $1.03(0.49$ to 2.17$)$ \\
\hline Mixed & 1.41 (0.63 to 3.18$)$ & $1.18(0.51$ to 2.75$)$ & $0.95(0.25$ to 3.63$)$ & $1.53(0.51$ to 4.58$)$ \\
\hline Indian & $1.42(0.83$ to 2.42$)$ & $1.42(0.82$ to 2.47$)$ & $1.27(0.55$ to 2.97$)$ & $1.77(0.84$ to 3.74$)$ \\
\hline Pakistani & $6.05(3.43$ to 10.68$) * * *$ & $4.81(2.67$ to 8.69$) * * *$ & $5.99(2.59$ to 13.83$) * * *$ & $4.63(1.93$ to 11.10$) * *$ \\
\hline Bangladeshi & $2.30(1.10$ to 4.81$)$ * & 1.88 (0.87 to 4.04$)$ & $2.43(0.90$ to 6.58$)$ & $1.41(0.38$ to 5.14$)$ \\
\hline Other Asian & $0.86(0.28$ to 2.59$)$ & $0.86(0.28$ to 2.65$)$ & $0.50(0.06$ to 4.17$)$ & $1.18(0.29$ to 4.81$)$ \\
\hline Caribbean & 1.25 (0.75 to 2.09$)$ & 0.85 (0.51 to 1.44$)$ & $0.82(0.37$ to 1.82$)$ & 0.91 (0.45 to 1.82$)$ \\
\hline African & $2.12(1.05$ to 4.29$)$ * & 1.32 (0.64 to 2.72$)$ & $2.27(0.82$ to 6.30$)$ & $0.90(0.32$ to 2.57$)$ \\
\hline Any other ethnic group & 2.45 (1.41 to 4.25$)$ ** & $2.04(1.15$ to 3.61$)$ * & $2.66(1.13$ to 6.27$)$ * & $1.81(0.83$ to 3.95$)$ \\
\hline \multicolumn{5}{|c|}{ Time resident in the UK (ref: born in the UK) } \\
\hline Less than 10 years & 1.07 (4.25 to 2.83$)$ & 0.92 (0.34 to 2.48$)$ & $0.72(0.17$ to 3.08$)$ & $1.28(0.31$ to 5.30$)$ \\
\hline $10-39$ years & $1.22(0.76$ to 1.97$)$ & $1.10(0.67$ to 1.81$)$ & $0.48(0.21$ to 1.10$)$ & $1.77(0.93$ to 3.38$)$ \\
\hline $40-49$ years & $1.19(0.78$ to 1.84$)$ & $1.14(0.73$ to 1.79$)$ & $0.88(0.44$ to 1.76$)$ & $1.29(0.71$ to 2.34$)$ \\
\hline $50+$ years & $1.31(0.92$ to 1.86$)$ & $1.30(0.91$ to 1.87$)$ & $1.00(0.57$ to 1.76$)$ & $1.61(1.01$ to 2.59$)$ * \\
\hline \multicolumn{5}{|l|}{ Income quintile (ref: top) } \\
\hline Fourth quintile & & $1.53(1.25$ to 1.89$) * * *$ & $1.63(1.24$ to 2.13$) * * *$ & $1.32(0.95$ to 1.84$)$ \\
\hline Third quintile & & $1.31(1.06$ to 1.62$)$ * & $1.61(1.22$ to 2.13$)$ ** & $0.98(0.70$ to 1.35$)$ \\
\hline Second quintile & & $1.12(0.90$ to 1.39$)$ & $1.51(1.11$ to 2.05$)$ ** & $0.81(0.58$ to 1.11$)$ \\
\hline Bottom & & $1.03(0.82$ to 1.29$)$ & $1.52(1.10$ to 2.11$)$ * & $0.73(0.53$ to 1.00$)$ \\
\hline \multicolumn{5}{|c|}{ Deprivation (ref: first quartile (lowest)) } \\
\hline Second quartile & & $1.59(1.29$ to 1.95$) * * *$ & $1.41(1.07$ to 1.86$)$ * & $1.81(1.34$ to 2.45$) * * *$ \\
\hline Third quartile & & $2.58(2.13$ to 3.13$) * * *$ & 2.60 (1.99 to 3.38$) * * *$ & $2.56(1.92$ to 3.41$) * * *$ \\
\hline Fourth quartile & & $4.07(3.38$ to 4.90$) * * *$ & $3.66(2.82$ to 4.75$) * * *$ & $4.34(3.32$ to 5.68$) * * *$ \\
\hline
\end{tabular}

pattern of reporting poor self-rated health among EM groups and white British does not change substantially, but the health differentials between Irish, Caribbean, African and white British individuals become not significant. Older people in the top income quintile show significantly lower odds of reporting poor self-rated health than those in the fourth and third income quintiles. Older people experiencing a higher degree of deprivation are more likely to report poor self-rated health.

When the model was run separately for men and women, the results remained broadly similar, with a few exceptions: only older men of Pakistani and 'any other' ethnic heritage are more likely to report poor self-rated health than the older white British men. Older Pakistani women also face higher odds (OR 4.63) of poor self-rated health than the older white British women. No significant differences are found for the length of time older men have been resident in the UK, but non-UK-born older women who have been in the UK for over 50 years are $61 \%$ more likely to report poor health than women born in the UK.

\section{DISCUSSION}

This study revisited earlier analysis of the patterns of ethnic inequalities in health in later life, reconfirming that health inequalities between ethnic groups are greatest in later life, while at the same time highlighting that there remain significant differences in the socioeconomic status of older people from
EM groups. For instance, Pakistani and Bangladeshi elders are more likely to be among the poorest in terms of income and also more likely to experience higher deprivation. The increasing ethnic inequalities in health with age in the UK could reflect the accumulation of risks over the life course and the long-term consequences of exposure to hazards (such as socioeconomic disadvantage, poor healthcare experience and racial discrimination) in early life, ${ }^{9}{ }^{15}$ acting as a reminder that reducing the gap of ethnic inequalities in health through reducing the hazards that ethnic communities may face in early life could help narrow the health gap in later life. Lower socioeconomic position, however, is not only an issue for EM communities at younger ages, ${ }^{9}{ }^{11}$ but remains an issue for older individuals from ethnic minorities. 2022

Results from the multivariate analysis reveal that there are significant differences in the patterns of both limiting health and self-rated health among older people from different ethnic minorities, and that these remain even after taking socioeconomic disadvantage into account. The results in this study are remarkably consistent with Evandrou's earlier study (2000) which indicated that BME elders were more likely to experience health inequalities and disadvantage, with Pakistani and Bangladeshi elderly people being particularly vulnerable in this respect. Evandrou ${ }^{20}$ drew on data from the early to mid-1990s, whereas the current study uses data from 2009 to 2011. It is of concern that the passage of time appears to have 
done little to narrow the gap, despite the policy focus on addressing the social determinants of health during the past two decades. ${ }^{33}$ At the end of the millennium, Saving Lives: Our Healthier Nation highlighted that 'in addressing the health of people from BME groups we need a new approach'. ${ }^{34}$ Nearly 20 years on, it remains clear that a renewed effort is required if we are to ensure that the growing cohorts of UK BME elders do not face the same health disadvantage in later life in the third decade of the 21st century as they did in the closing decade of the 20th century. Elderly people from the Pakistani and Bangladeshi communities, in particular, should be at the centre of public policies promoting good health as they are more likely to experience lower socioeconomic status, more likely to suffer discrimination in accessing health services, ${ }^{17}$ and have persistently reported higher levels of limiting long-term illness than white British individuals over the period $1991-2011 .^{8}$

\section{Limitations}

Although this study provides important updated results of the patterns of ethnic inequalities in health in later life, limitations remain. The data on socioeconomic disadvantage reflect BME elders' current situation; the survey did not include information on the socioeconomic disadvantage experienced by individuals in their earlier life or the length of exposure to such disadvantage. Moreover, without information on the work history of older people who migrated to the UK, the ability to investigate whether migration could have resulted in upward social mobility among BME individuals and the associated impact on health outcomes is limited. Furthermore, it should be recognised that the variables on self-reported health and limiting health are based on subjective interpretations of the questions among respondents, which may have an impact on the differences shown.

In summary, this study provides updated evidence of significant ethnic differences in self-rated health and limiting health in later life. BME elders are more likely to report their health as limiting their typical activities and to report poor self-rated health than white British elders. Socioeconomic factors (income and deprivation) play an important mediating role, but a health disadvantage remains as Indian, Pakistani and Bangladeshi elders consistently report worse health than white British persons.

\section{What is already known on this subject}

- Previous research on ethnic differentials in health outcomes has highlighted that individuals from black and minority ethnic (BME) groups are more likely to report poorer general health and a limiting long-term illness than the general white British population.

- Ethnic inequalities in health in later life have received less attention. A previous study by Evandrou, using data from 1991 to 1996, found BME elders reported worse health than the white British majority population, with Pakistani and Bangladeshi elders consistently reporting the worst health outcomes in terms of long-standing illness, ill health and 'not good' general health status. However, despite the ageing of the BME population, since the publication of Evandrou (2000) there have been no further studies that have explicitly examined health inequalities among ethnic groups in later life.

\section{What this study adds}

- This study provides an updated picture of ethnic inequalities in later life at the end of the first decade of the 21st century. Using a nationally representative sample for 20092011, results from the multivariate analysis highlight that older people from most ethnic minority groups (excluding Irish, other white and other Asian) are more likely to report their health as limiting their typical activities and to report poor self-rated health than white British older people. After controlling for income and deprivation, health inequalities become narrower but a health disadvantage remains, with Indian, Pakistani and Bangladeshi elders consistently reporting worse health than white British persons.

- The length of time spent in the UK itself does not have a direct impact on health for men or in the model for both genders. However, women who have been in the UK between 10 and 19 years and who are more than 50 years of age are significantly more likely to report limiting health and poor health, respectively, than those born in the UK.

- The study provides a timely reminder that despite a policy focus on addressing the social determinants of health during the past two decades, more work needs to be done to tackle both socioeconomic and health disadvantages in later life among BME groups in the UK. This will become even more pressing with the ageing of the BME population.

Contributors This study was conceived and designed by all four authors. ZF conducted the statistical analyses. All authors contributed to the draft and the critical revisions of the manuscript, and approved the final submitted version.

Funding This research was supported by the AGEGlobe Network funded under the ESRC Ageing and Well-being in a Globalising World (grant number ES/K005979/1), the ESRC Centre for Population Change (grant number ES/K007394/1) and the EPSRC Care Life Cycle project (grant number EP/H021698/1) at the University of Southampton.

Competing interests None declared.

Provenance and peer review Not commissioned; externally peer reviewed.

Open Access This is an Open Access article distributed in accordance with the Creative Commons Attribution Non Commercial (CC BY-NC 4.0) license, which permits others to distribute, remix, adapt, build upon this work non-commercially, and license their derivative works on different terms, provided the original work is properly cited and the use is non-commercial. See: http://creativecommons.org/ licenses/by-nc/4.0/

\section{REFERENCES}

1 Department of Health (DH). Tackling health inequalities: 10 years on-a review of developments in tackling health inequalities in England over the last 10 years. London: Department of Health, 2009.

2 Karlsen S, Nazroo JY. Religious and ethnic differences in health: evidence from the Health Surveys for England 1999 and 2004. Ethn Health 2010;15:549-68.

3 Randhawa G. Tackling health inequalities for minority ethnic groups: challenges and opportunities. A Race Equality Foundation Briefing Paper. Race Equality Foundation, 2007. http://www.better-health.org.uk/sites/default/files/briefings/downloads/ health-brief6.pdf (accessed May 2015).

4 Smith GD, Chaturvedi N, Harding S, et al. Ethnic inequalities in health: a review of UK epidemiological evidence. Crit Public Health 2000;10:375-408.

5 Becker E, Boreham R, Chaudhury M, et al. Health survey for England 2004. The Information Centre, 2006. http://www.google.co.uk/url?sa=t\&rct=j\&q=\&esrc=s\& source $=$ web\&cd=1\&ved=0CCEQFjAAahUKEwiH5sDh57IAhUHThQKHdykAzA\& url=http \%3A\%2F\%2Fwww.hscic.gov.uk\%2Fcatalogue\%2FPUB01170\%2Fheasurv-ethn-min-eng-2004-rep-v1.pdf\&usg=AFQjCNFt4gVICUbPDreWkDirNwCONX 6xjw\&sig2=iSBGgLfPxzCDVZqx1vSMQg (accessed Sep 2015).

6 Smith NR, Kelly YJ, Nazroo JY. Intergenerational continuities of ethnic inequalities in general health in England. J Epidemiol Community Health 2009;63:253-8. 
7 Harding S, Balarajan R. Limiting long-term illness among black Caribbeans, black Africans, Indians, Pakistanis, Bangladeshis and Chinese born in the UK. Ethn Health 2000;5:41-6.

8 Bécares L. Which ethnic groups have the poorest health? Ethnic health inequalities M 1991 to 2011. Centre on Dynamics of Ethnicity (CODE) Briefing. Manchester: Manchester University, 2013.

9 Nazroo JY. The structuring of ethnic inequalities in health: Economic position, racia discrimination, and racism. Am J Public Health 2003;93:277-84.

10 Department for Work and Pensions (DWP). Labour market status by ethnic group. https://www.gov.uk/government/statistics/labour-market-status-by-ethnic-groupjune-2014 (accessed May 2015).

11 Poverty site. http://www.poverty.org.uk/ (accessed May 2015).

12 Wild S, McKeigue P. Cross sectional analysis of mortality by country of birth in England and Wales, 1970-92. BMJ 1997;314:705-10.

13 Emerson E, Hatton C. Socioeconomic disadvantage, social participation and networks and the self-rated health of English men and women with mild and moderate intellectual disabilities: cross sectional survey. Eur J Public Health. 2008;18:31-7.

14 Bartley M, Sacker A, Clarke P. Employment status, employment conditions, and limiting illness: prospective evidence from the British household panel survey 19912001. J Epidemiol Community Health 2004;58:501-6.

15 Hudson DL, Puterman E, Bibbins-Domingo K, et al. Race, life course socioeconomic position, racial discrimination, depressive symptoms and self-rated health. Soc Sci Med 2013;97:7-14.

16 Nazroo JY, Falaschetti E, Pierce M, et al. Ethnic inequalities in access to and outcomes of healthcare: analysis of the Health Survey for England. J Epidemiol Community Health 2009;63:1022-7.

17 Aspinall PJ, Jacobson B. Ethnic disparities in health and health care: a focused review of the evidence and selected examples of good practice. London: London Health Observatory, 2004.

18 Karlsen S, Nazroo JY. Relation between racial discrimination, social class, and health among ethnic minority groups. Am J Public Health 2002;92:624-31.
19 Smith N, Grundy E. Time period trends in ethnic inequalities in limiting long term illness in England and Wales. Ethn Inequalities Health Soc Care 2011;4:200-9.

20 Evandrou M. Ethnic inequalities in health in later life. Health Stat Q 2000;8:20-8.

21 Vlachantoni $A$, Feng $Z$, Evandrou $M$, et al. Ethnic elders and pension protection in the UK. Ageing Soc. Forthcoming 2016.

22 Evandrou M. Social inequalities in later life: the socio-economic position of older people from ethnic minority groups in Britain. Popul Trends 2000;101:11-18.

23 Office for National Statistics (ONS). Focus on ethnicity and identity. London: Office for National Statistics, 2005.

24 Office for National Statistics (ONS). 2011 Census: key statistics for England and Wales, March 2011. Statistical bulletin. London: Office for National Statistics, 2012

25 Lievesley N. The future ageing of the ethnic minority population of England and Wales. London: Runnymede and the Centre for Policy on Ageing, 2010.

26 Department for Work and Pensions (DWP). The pensioners' income series, United Kingdom, 2012/13. London: Department for Work and Pensions, 2014.

27 Bajekal M, Blane D, Grewal I, et al. Ethnic differences in influences on quality of life at older ages: a quantitative analysis. Ageing Soc 2004;24:709-28.

28 Boreham R, Boldysevaite D, Killpack C. UKHLS wave 1 technical report. National Centre for Social Research. Essex: Institute for Social and Economic Research, 2012.

29 Understanding Society. UK household longitudinal study: wave 1, 2009-2010 user manual. Essex: University of Essex, 2011.

30 Wu Z, Schimmele CM. Psychological disposition and self-reported health among the 'oldest-old' in China. Ageing Soc 2006;26:135-51.

31 Manor 0, Matthews S, Power C. Self-rated health and limiting longstanding illness: inter-relationships with morbidity in early adulthood. Int J Epidemiol 2001;30:600-7.

32 Berthoud R, Bryan M. Income, deprivation and poverty: a longitudinal analysis. J Soc Policy 2011:40:135-56.

33 Wilkinson R, Marmot M, ed. The social determinants of health: the solid facts. 2nd edn. Geneva: World Health Organization Europe, 2003.

34 Department of Health (DH). Saving lives: our healthier nation. London: The Stationery Office, 1999. 